This article is licensed under the Creative Commons Attribution-NonCommercial 4.0 International License (CC BY-NC) (http://www.karger.com/Services/OpenAccessLicense). Usage and distribution for commercial purposes requires written permission.

\title{
Multiple Small Intestine Ulcers with Desquamation of the Fingers
}

\author{
Azusa Kawasaki Kunihiro Tsuji Hisashi Doyama \\ Department of Gastroenterology, Ishikawa Prefectural Central Hospital, Kanazawa, Japan
}

\section{Keywords}

Small intestine - Ulcers · Desquamation of the fingers · Yersinia pseudotuberculosis - Infection . Kawasaki disease

\begin{abstract}
A 73-year-old female was admitted to our hospital with abdominal pain and diarrhea. Computed tomography detected distension of the small intestine. A palmar erythema, multiple oral ulcers, and desquamation of the fingers appeared after hospitalization. Small-bowel endoscopic images showed multiple ulcers. We attributed this case to infection with Yersinia pseudotuberculosis based on the changes in $Y$. pseudotuberculosis antibody titers throughout the course of the illness. This report is valuable, as it illustrates the endoscopic characteristics of a Y. pseudotuberculosis infection with skin lesion and ileus, which may enable us to deepen the pathologic understanding of this disease.




\section{Case Reports in Gastroenterology}

Case Rep Gastroenterol 2017;11:452-461

DOI: $10.1159 / 000479222$

(C) 2017 The Author(s). Published by S. Karger AG, Basel www.karger.com/crg

Kawasaki et al.: Multiple Small Intestine Ulcers with Desquamation of the Fingers

\section{Introduction}

Advances in medical device development have enabled the evaluation of lesions in the small intestine that were previously difficult to assess. Small intestine ulcers are representative small-intestine lesions, and their etiology can be idiopathic, infectious, drug-induced (aspirin and other NSAIDs), or avasculitis-related [1]. The two main Yersinia species that are known to cause abdominal symptoms are Yersinia enterocolitica and Yersinia pseudotuberculosis. Reportedly, Y. pseudotuberculosis infection is associated with Kawasaki disease-like constitutional symptoms [2-5]. However, the underlying pathogenic mechanism is unclear. Additionally, it is said that there are no clear differences in endoscopic images of patients with an infection by either bacteria [6].

We report a case of multiple small intestine ulcers and desquamation of the fingers. After thorough investigations, the characteristics of our case did not meet the diagnostic criteria for Kawasaki disease. Additionally, we thought that the etiology in this case was very likely to be $Y$. pseudotuberculosis infection given its frequent occurrence in small intestine ulcers and the change in $Y$. pseudotuberculosis antibody titers in pair serum samples of the patient during the course of the illness. Both Kawasaki disease and Y. pseudotuberculosis infection are characterized by an intestinal tract lesion as the main constitutional symptom. However, to the best of our knowledge, no previous reports have included endoscopic images of intestinal lesions caused by $Y$. pseudotuberculosis infection. Thus, it is important to deepen the pathologic understanding of these lesions by reporting the endoscopic images associated with this disorder.

\section{Case Report}

A 73-year-old female was admitted to our hospital on May 2015. She presented abdominal pain and diarrhea during 5 days, for which she was examined and treated by a primary care physician. As her symptoms did not improve, she was admitted to our hospital. She had a history of cholecystectomy 20 years earlier. She had no history of smoking or alcohol abuse. She did not take any medication. Furthermore, she denied drinking well water.

On admission, her temperature was $37.7^{\circ} \mathrm{C}$, her pulse was 90 beats $/ \mathrm{min}$, and her blood pressure was 143/66 mm Hg. Her abdomen was distended, but no other abnormality was observed upon physical examination. Laboratory testing on admission showed an increased C-reactive protein level (Table 1). Distension of the small intestine was also detected on computed tomography (CT).

The patient was initially managed conservatively. She received ceftriaxone $1 \mathrm{~g} /$ day by intravenous drip infusion. Her C-reactive protein levels improved transiently and then continued to increase. Several other tests were performed but all yielded negative results (Table 2), for example: bacterial cultures of blood and stool, antinuclear antibodies, cytoplasmic anti-neutrophil cytoplasmic antibody, myeloperoxidase ANCA, anti-double stranded DNA IgG antibody, enzyme-linked immunospot assay (T-SPOT ${ }^{\circledR} . T B$ ), among others. A CT scan performed on hospitalization day 7 showed that the distension of the small intestine continued to worsen. Abdominal distension occurred as a consequence of intestinal tract distension, and she thus underwent ileus tube insertion. On hospitalization day 12 , her symptoms 


\section{Case Reports in Gastroenterology}

Case Rep Gastroenterol 2017;11:452-461

DOI: $10.1159 / 000479222$

(C) 2017 The Author(s). Published by S. Karger AG, Basel www.karger.com/crg

Kawasaki et al.: Multiple Small Intestine Ulcers with Desquamation of the Fingers

began to improve. Fluoroscopy via the tube showed that there was no obvious stenosis, but there was stagnation of the contrast medium. On hospitalization day 13, we performed a small-bowel endoscopy. We obtained endoscopic images of the affected area that showed a variety of lesions, including multiple ulcers running along the direction of the minor axis, map-like ulcers, and portions of disrupted mucous membrane involving the entire circumference of the ileum (Fig. 1). On hospitalization day 20, we performed an esophagogastroduodenoscopy. We obtained endoscopic images of the mucous membrane lesions presenting as redness, erosions, and an ulcer extending from the duodenal angulus to the second part of the duodenum (Fig. 2). However, no specific findings were obtained pathologically (Fig. 3). On hospitalization day 9, the patient presented a palmar erythema, with the subsequent appearance of multiple oral ulcers on hospitalization day 11. Desquamation of the fingers occurred on hospitalization day 13 (Fig. 4). We suspected adult-onset Kawasaki disease or $Y$. pseudotuberculosis infection as possible etiologies for the patient's condition based on the presence of finger desquamation. A coronary artery CT and an echocardiography were performed, but these examinations did not reveal any abnormalities. Additionally, there was no evidence of coronary aneurysm. Thus, based on the clinical findings, our case did not meet the diagnostic criteria for Kawasaki disease. Antibody titers of Y. pseudotuberculosis were measured in pair serum samples showing an 80-fold increase on hospitalization day 11; these titers decreased thereafter (Table 3). Conservative medical treatment was continued and the patient's symptoms gradually improved. She was discharged after 44 days of hospitalization.

\section{Discussion}

We reported a case of multiple small intestine ulcers associated with desquamation of the fingers. To the best of our knowledge, our report is the first to describe such a presentation of $Y$. pseudotuberculosis infection and provide endoscopic images of the intestinal lesions. Although we were unable to isolate the bacterium, it is extremely likely that this was a case of $Y$. pseudotuberculosis infection for the following reasons.

First, the patient presented desquamation of the fingers. Based on the differential diagnosis, we considered Kawasaki disease and Y. pseudotuberculosis infection as the possible underlying etiologies. Desquamation of the fingers is highly specific for Kawasaki disease and $Y$. pseudotuberculosis infection. This symptom is seen in $96 \%$ of Kawasaki disease cases and in $83 \%$ of $Y$. pseudotuberculosis infection cases [7, 8].

Second, it is difficult to isolate the bacteria in cases of $Y$. pseudotuberculosis infection. We performed bacterial cultures of stool, but the results were negative. The presence of ileus precluded us from performing bacterial cultures of biopsy samples early on. Although a lowtemperature culture is ideal, even if the culture is maintained at a low temperature and preferential segregation culture medium is used, there is only about a $40 \%$ likelihood of isolating these bacteria [9]. Since we did not consider Y. pseudotuberculosis infection early during the disease course in the present case, we were unable to conduct a low-temperature culture.

Third, after measuring Y. pseudotuberculosis antibody titers in pair serum samples of the patient, we observed a rise in the initial levels with a subsequent drop. We were not able to examine initial antibody titers given the delay in establishing the primary diagnosis and the 


\section{Case Reports in Gastroenterology} \begin{tabular}{l|l}
\hline Case Rep Gastroenterol 2017;11:452-461 \\
\hline DOI: $10.1159 / 000479222$ & $\begin{array}{l}\text { ( ) 2017 The Author(s). Published by S. Karger AG, Basel } \\
\text { www.karger.com/crg }\end{array}$ \\
\hline
\end{tabular}

Kawasaki et al.: Multiple Small Intestine Ulcers with Desquamation of the Fingers

titer change did not reach 160 -fold increase. However, we strongly consider that Y. pseudotuberculosis was the causal agent based on the 4-fold antibody titer rise in only one type of the serum group. It seems unlikely that such change in antibody titers was attributable to the presence of bacteria other than $Y$. pseudotuberculosis.

We were able to document the intestinal lesions by endoscopy. The characteristic endoscopic images of enteritis by Yersinia species comprise terminal ileitis, scattered mucosal ulcers with white mossy appearance, ileocecal valve swelling, aphthous ulcers on the right large intestine, and punctate irregular redness [10]. It has been reported that there is no clear difference between the endoscopic characteristics and distribution of lesions by $Y$. enterocolitica and Y. pseudotuberculosis [6]. Notably, endoscopic images of cases similar to ours have not been reported previously. In a previous report, the main lesion of enteritis by Yersinia was terminal ileitis [11, 12]. Matsumoto et al. [12] reported that these lesions are changes of the solitary lymph nodes and Peyer's patch. In the present case, the lesions were extensive in the duodenum and widespread in the small intestine. Furthermore, the endoscopic images were also different from the representative lesions of $Y$. pseudotuberculosis infection reported so far.

Some patients with Kawasaki disease and $Y$. pseudotuberculosis infection may present with ileus, as in the present case [13-16]. Miyake et al. [15] reported that 7 of 310 patients with Kawasaki disease developed pseudo-obstruction. In this case, we observed multiple ulcers running along the direction of the minor axis, map-like ulcers, and mucous membrane disruption involving the entire circumference of the ileum. The mechanism of such changes has been proposed to be mesenteric artery vasculitis with bowel ischemia and associated dysfunction of the myenteric plexus $[15,17]$.

Pathological examination of the ischemic changes also shows nonspecific inflammatory cell infiltrates consisting of lymphocytes and plasma cells [18]. The present case shows pathologic findings of ischemia. The endoscopic image of the present case closely resembles ischemic enteritis (Fig. 5). Therefore, we consider that the endoscopic images of the intestinal lesions in the present case support the proposed mechanism of ischemia leading to ileus secondary to $Y$. pseudotuberculosis infection. The condition may worsen depending on which area is affected in relation with the mesentery. Furthermore, annular ulcers were mixed with map-like ulcers and villi atrophy.

Kawasaki disease is a systemic vasculitis and some cases of $Y$. pseudotuberculosis infection show clinical conditions similar to Kawasaki disease. However, the etiology of the Kawasaki disease remains largely unclear. Previous studies have reported an association between Kawasaki disease and $Y$. pseudotuberculosis infection [2-5]. In a previous report, $Y$. pseudotuberculosis infection was identified in 9.3\% of patients with Kawasaki disease [5]. Further, in some reports, Kawasaki disease diagnostic criteria were met in 8.8-16.6\% of cases with $Y$. pseudotuberculosis infections $[3,19]$. Some cases of $Y$. pseudotuberculosis infection present with skin lesions, and ileitis are thought to develop secondary to vasculitis triggered by infection. We think that the endoscopic images obtained in our case are the first to have captured these changes.

In conclusion, we observed $Y$. pseudotuberculosis infection presenting with skin lesions and ileus on endoscopic images. These endoscopic images suggested the presence of ischemic changes. Thus, our findings seem to indicate that some cases of $Y$. pseudotuberculosis infection, particularly those presenting with skin lesions and ileus, may develop vasculitis trig- 
gered by the infection. Further, it is important to consider not only the characteristics of $Y$. pseudotuberculosis infection, but also those of Kawasaki disease, in order to understand these conditions, which have overlapping presentations in some cases. Some cases of Kawasaki disease involve pseudo-obstruction, as in the present case. Additionally, it was difficult to further the understanding of this condition, as it was considered to be a childhood illness only. We consider that even in Kawasaki disease with pseudo-obstruction, there is a possibility that the endoscopic images are similar to those observed in this case. This report is valuable, as it illustrates the endoscopic characteristics of a Y. pseudotuberculosis infection with systemic manifestations, which may enable us to deepen the pathologic understanding of this disease.

\section{Acknowledgements}

We gratefully acknowledge Satohiro Matsumoto (Department of Gastroenterology, Saitama Medical Center, Jichi Medical University, Saitama, Japan) for his advice. The authors also thank the Clinical Research Support Team Jichi (CRST) for their advice.

\section{Statement of Ethics}

Informed consent was obtained for this case report.

\section{Disclosure Statement}

The authors declare that they have no conflicts of interest.

\section{References}

1 Freeman HJ: Multifocal stenosing ulceration of the small intestine. World J Gastroenterol 2009;15:4883-4885

72 Konishi N, Baba K, Abe J, et al: A case of Kawasaki disease with coronary artery aneurysms documenting Yersinia pseudotuberculosis infection. Acta Paediatr 1997;86:661-664.

-3 Baba K, Takeda N, Tanaka M: Cases of Yersinia pseudotuberculosis infection having diagnostic criteria of Kawasaki disease. Contrib Microbiol Immunol 1991;12:292-296.

-4 Sato K, Ouchi K, Komazawa M: Ampicillin vs. placebo for Yersinia pseudotuberculosis infection in children. Pediatr Infect Dis J 1988;7:686-689.

5 Tahara M, Baba K, Waki K, et al: Analysis of Kawasaki disease showing elevated antibody titres of Yersinia pseudotuberculosis. Acta Paediatr 2006;95:1661-1664.

6 Okuyama Y, Shimizu S, Kohashi M, et al: Yersinia enterocolitis (in Japanese with English abstract). Stomach Intestine 2008;43:1621-1628.

7 Wolff AE, Hansen KE, Zakowski L: Acute Kawasaki disease: not just for kids. J Gen Intern Med 2007;22:681-684.

$8 \quad$ Satou K: Yersinia infection (in Japanese with English abstract). Jpanes J Pediatr Med 1983;21:11791183.

9 Matsumoto S, Hattori S: Yersinia infection (in Japanese with English abstract). Jpn J Pediatr Med 2002;34:920-923. 


\section{Case Reports in Gastroenterology}

\begin{tabular}{l|l}
\hline Case Rep Gastroenterol 2017;11:452-461 \\
\hline DOI: $10.1159 / 000479222$ & $\begin{array}{l}\text { (c) 2017 The Author(s). Published by S. Karger AG, Basel } \\
\text { www.karger.com/crg }\end{array}$ \\
\hline
\end{tabular}

Kawasaki et al.: Multiple Small Intestine Ulcers with Desquamation of the Fingers

10 Takahashi M, Ijyuu M: A case of Yersinia enterocolitis (in Japanese with English abstract). Gastroenterol Endosc 2013;55:1866-1867.

11 Rutgeerts P, Geboes K, Ponette E, et al: Acute infective colitis caused by endemic pathogens in Western Europe: endoscopic features. Endoscopy 1982;14:212-219.

12 Matsumoto T, Iida M, Matsui T, et al: Endoscopic findings in Yersinia enterocolitica enterocolitis. Gastrointest Endosc 1990;36:583-587.

13 Zulian F, Falcini F, Zancan L, et al: Acute surgical abdomen as presenting manifestation of Kawasaki disease. J Pediatr 2003;142:731-735.

14 Akikusa JD, Laxer RM, Friedman JN: Intestinal pseudoobstruction in Kawasaki disease. Pediatrics 2004;113:504-506.

15 Miyake T, Kawamori J, Yoshida T, et al: Small bowel pseudo-obstruction in Kawasaki disease. Pediatr Radiol 1987;17:383-386.

-16 Franken EA Jr, Kleiman MB, Norins AL, et al: Intestinal pseudo-obstruction in mucocutaneous lymphnode syndrome. Radiology 1979;130:649-651.

17 Beiler HA, Schmidt KG, von Herbay A, et al: Ischemic small bowel strictures in a case of incomplete Kawasaki disease. J Pediatr Surg 2001;36:648-650.

18 Okado Y, Takagi Y, et al: Ischemic enteritis (in Japanese with English abstract). Stomach Intestine 2016;51:1717-1719.

19 Sato K, Ouchi K, Taki M: Yersinia pseudotuberculosis infection in children, resembling Izumi fever and Kawasaki syndrome. Pediatr Infect Dis 1983;2:123-126.

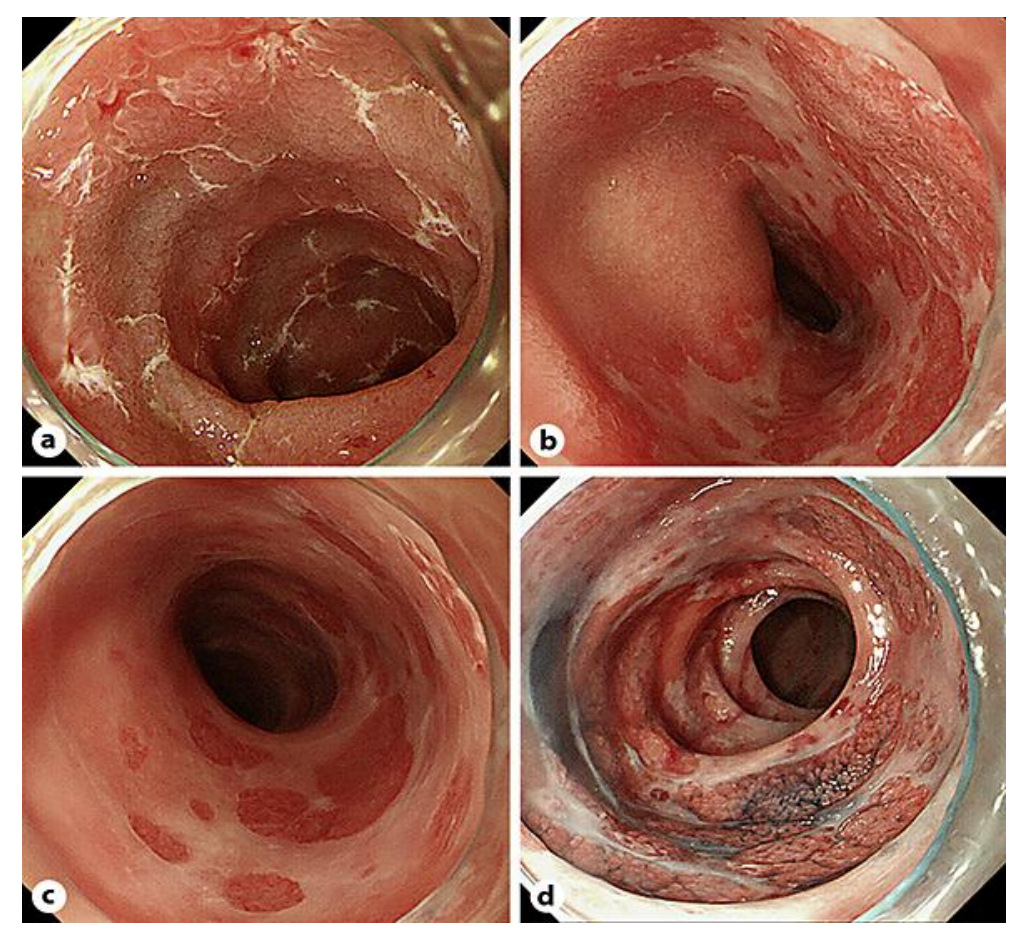

Fig. 1. a Small-bowel endoscopy shows multiple ulcers running along the direction of the minor axis of the ileum. b Small-bowel endoscopy shows map-like ulcers in the ileum. c, d Small-bowel endoscopy shows mucous membrane disruption involving the entire circumference of the ileum. 


\section{Case Reports in Gastroenterology}
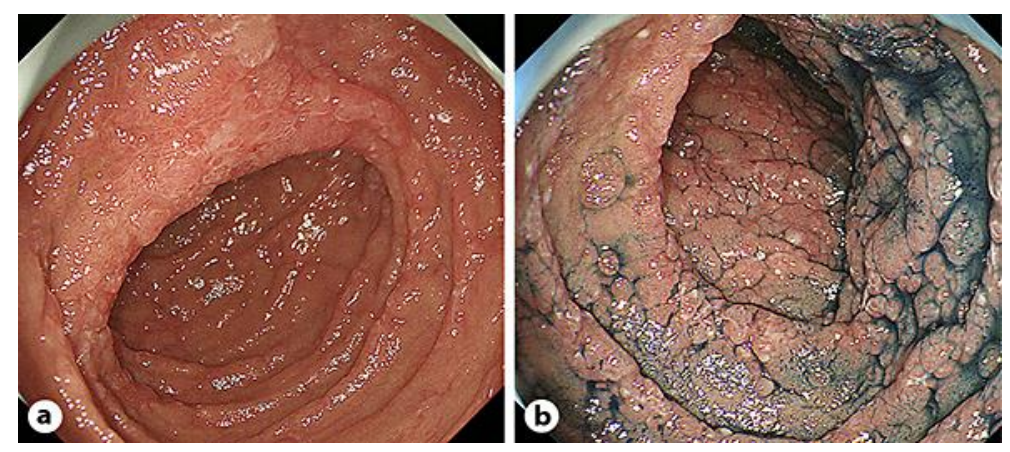

Fig. 2. a, b Esophagogastroduodenoscopy illustrates the mucous membrane disorder with redness, erosion, and ulcers in the duodenum.
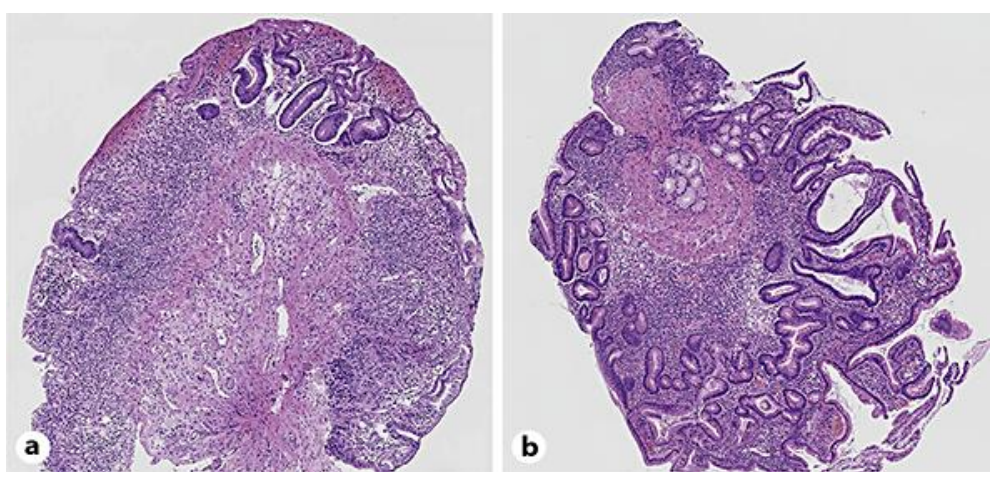

Fig. 3. a Pathological findings in the small intestine showing nonspecific inflammatory cell infiltrates consisting of lymphocytes and plasma cells. H\&E, original magnifiaction $\times 40$. $\mathbf{b}$ Pathological findings in the duodenum showing nonspecific inflammatory cell infiltrates consisting of lymphocytes and plasma cells. H\&E, original magnification $\times 40$. 


\section{Case Reports in Gastroenterology}

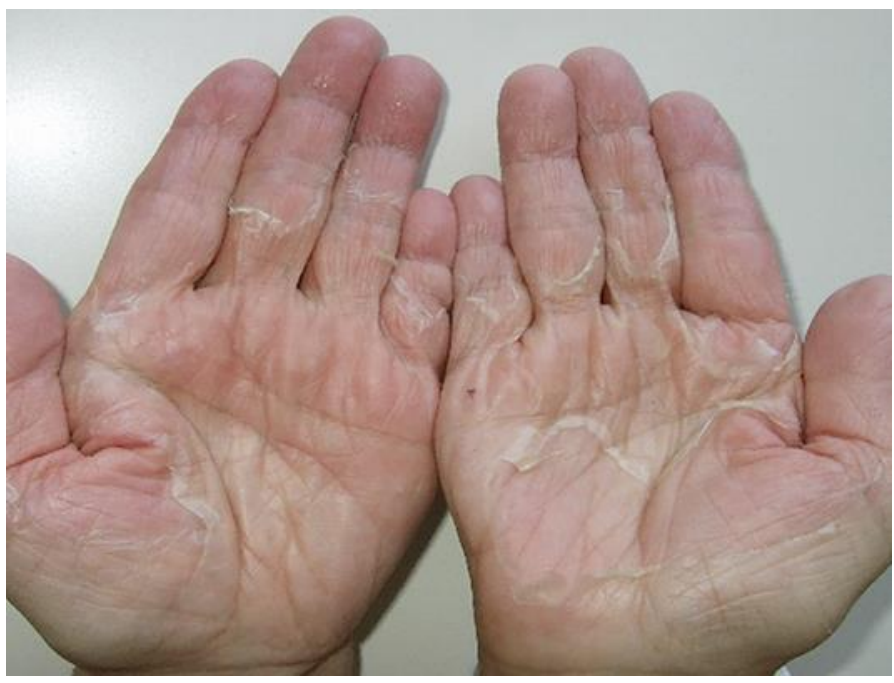

Fig. 4. Desquamation of the fingers occurred on hospitalization day 13.

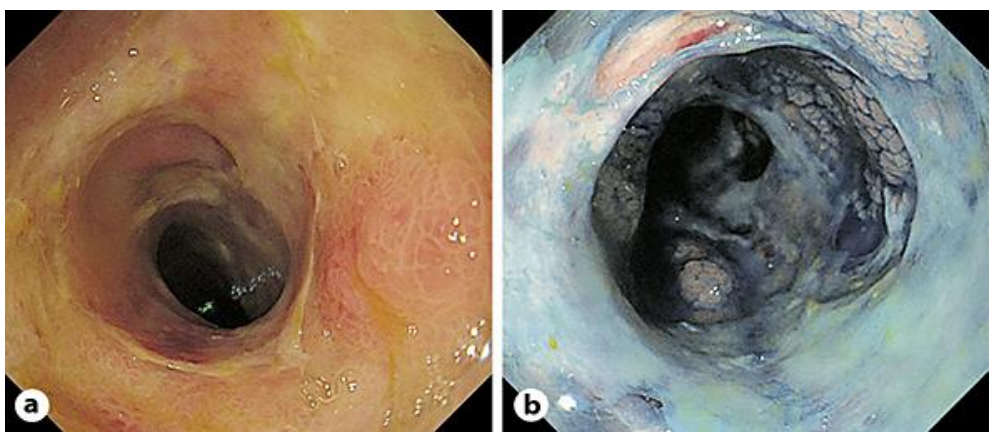

Fig. 5. a, b Endoscopic image showing ischemic enteritis (from Okado et al. [18]). 
Table 1. Laboratory data on admission

\section{Complete blood count}

White blood count (all), $\mu \mathrm{L} \quad 4,610$

Neutrophils, \%

84.4

Lymphocytes, \%

11.1

Monocytes, \%

4.3

Eosinophils, \% $\quad 0.0$

Basophils, \% 0.2

Red blood count, $\mu \mathrm{L} \quad 554 \times 10^{4}$

Hemoglobin, g/dL $\quad 16.0$

Hematocrit, \% $\quad 48.0$

Platelets, $\mu \mathrm{L} \quad 26.9 \times 10^{4}$

Blood biochemistry

Total protein, $\mathrm{g} / \mathrm{dL}$

Total bilirubin, $\mathrm{mg} / \mathrm{dL} \quad 0.50$

Alkaline phosphatase, U/L $\quad 146$

Aspartate aminotransferase, U/L $\quad 86$

Alanine aminotransferase, $\mathrm{U} / \mathrm{L} \quad 38$

Lactate dehydrogenase, U/L $\quad 584$

$\gamma$-glutamyltranspeptidase, U/L 22

ZTT, KU 1.5

TTT, KU $\quad 0.4$

Creatine kinase, U/L $\quad 996$

AMY, U/L 93

Blood urea nitrogen, $\mathrm{mg} / \mathrm{dL} \quad 22.5$

Creatinine, $\mathrm{mg} / \mathrm{dL} \quad 0.68$

$\mathrm{Na}, \mathrm{mEq} / \mathrm{L} \quad 131$

$\mathrm{K}, \mathrm{mEq} / \mathrm{L}$

$\mathrm{Cl}, \mathrm{mEq} / \mathrm{L}$

C-reactive protein, $\mathrm{mg} / \mathrm{dL} \quad 15.5$

PCT, ng/mL $\quad 0.5 \sim 2$

$\mathrm{C} 3, \mathrm{mg} / \mathrm{dL} \quad 90.1$

$\mathrm{C} 4, \mathrm{mg} / \mathrm{dL} \quad 23.7$

$\mathrm{IgA}, \mathrm{mg} / \mathrm{dL} \quad 132.8$

$\mathrm{IgG}, \mathrm{mg} / \mathrm{dL} \quad 503.4$

IgM, mg/dL $\quad 28.8$

CEA, ng/mL $\quad 1.5$

CA19-9, U/mL $\quad 7.1$


Table 2. Additional laboratory findings

$\begin{array}{ll}\text { Bacterial cultures } & \\ \quad \text { Blood } & \text { negative } \\ \text { Stool } & \text { negative } \\ \text { ANA, } \times & <40 \\ \text { C-ANCA, EU/L } & <1.0 \\ \text { P-ANCA, EU/L } & <1.0 \\ \text { ds-DNA-IgG, IU } / \mathrm{mL} & <1.2 \\ \text { ds-DNA-IgM, U/mL } & <1.0 \\ \text { ELISA (T-SPOT) } & \text { negative }\end{array}$

ANA, antinuclear antibodies; C-ANCA, cytoplasmic anti-neutrophil cytoplasmic antibody; P-ANCA, myeloperoxidase ANCA; ds-DNA-IgG, anti-doublestranded DNA IgG antibody; ds-DNA-IgM, antidouble-stranded DNA IgM antibody; ELISA, enzyme-linked immunospot assay.

Table 3. Change in Y. pseudotuberculosis antibody titer

\begin{tabular}{lc}
\hline Hospitalization day & Yp2a titer \\
\hline 11 & $1: 80$ \\
21 & $1: 40$ \\
25 & $<1: 20$ \\
\hline
\end{tabular}

Yp, Yersinia pseudotuberculosis. 